\title{
Correction to: Impact of the observed SST frequency in the model initialization on the BSISO prediction
}

\author{
Xueyan $\mathrm{Zhu}^{1} \cdot{\text { Xiangwen } \mathrm{Liu}^{2} \cdot \text { Anning Huang }}^{1}{ }^{10} \cdot$ Yang Zhou $^{3} \cdot$ Yang Wu$^{1} \cdot \mathrm{Zhipeng} \mathrm{Fu}^{1}$
}

Published online: 5 July 2021

(c) The Author(s) 2021

\section{Correction to: Climate Dynamics}

https://doi.org/10.1007/s00382-021-05761-5

In the original version of the article, the mathematical formula in Sect. 2.4 and the Fig. 14 has been wrongly published. The correct formula and Fig. 14 is given below:

(1) Mathematic Formula (to replace the second formula in Sect. 2.4 of paper)

The original article can be found online at https://doi.org/10.1007/ s00382-021-05761-5.

Xiangwen Liu

xwliu@cma.gov.cn

$\triangle$ Anning Huang

anhuang@nju.edu.cn

1 CMA-NJU Joint Laboratory for Climate Prediction Studies and State Key Laboratory of Severe Weather and Joint Center for Atmospheric Radar Research of CMA/NJU, School of Atmospheric Sciences, Nanjing University, Nanjing 210023, China

2 CMA-NJU Joint Laboratory for Climate Prediction Studies, National Climate Center, China Meteorological Administration, Beijing 100081, China

3 Collaborative Innovation Center on Forecast and Evaluation of Meteorological Disasters/Key Laboratory of Meteorological Disaster, Ministry of Education, Nanjing University of Information Science and Technology,

Nanjing 210044, China $\frac{\partial\langle m\rangle}{\partial t}=-\langle V \cdot \nabla m\rangle-\left\langle\omega \cdot \frac{\partial m}{\partial p}\right\rangle+\langle L W\rangle+\langle S W\rangle+L H+S H$

(2) Figure 14 (to replace the old Fig. 14 of paper). The original article has been updated. 
Fig. 14 Same as in Fig. 11, but for the intraseasonal anomalies of $\mathbf{a}$ precipitation and $\mathbf{b}$ surface latent heat fux for the strong BSISO cases with wet-to-dry (WD), persistent-wet (PW) and persistent-dry (PD) phase variation (a) Precipitation

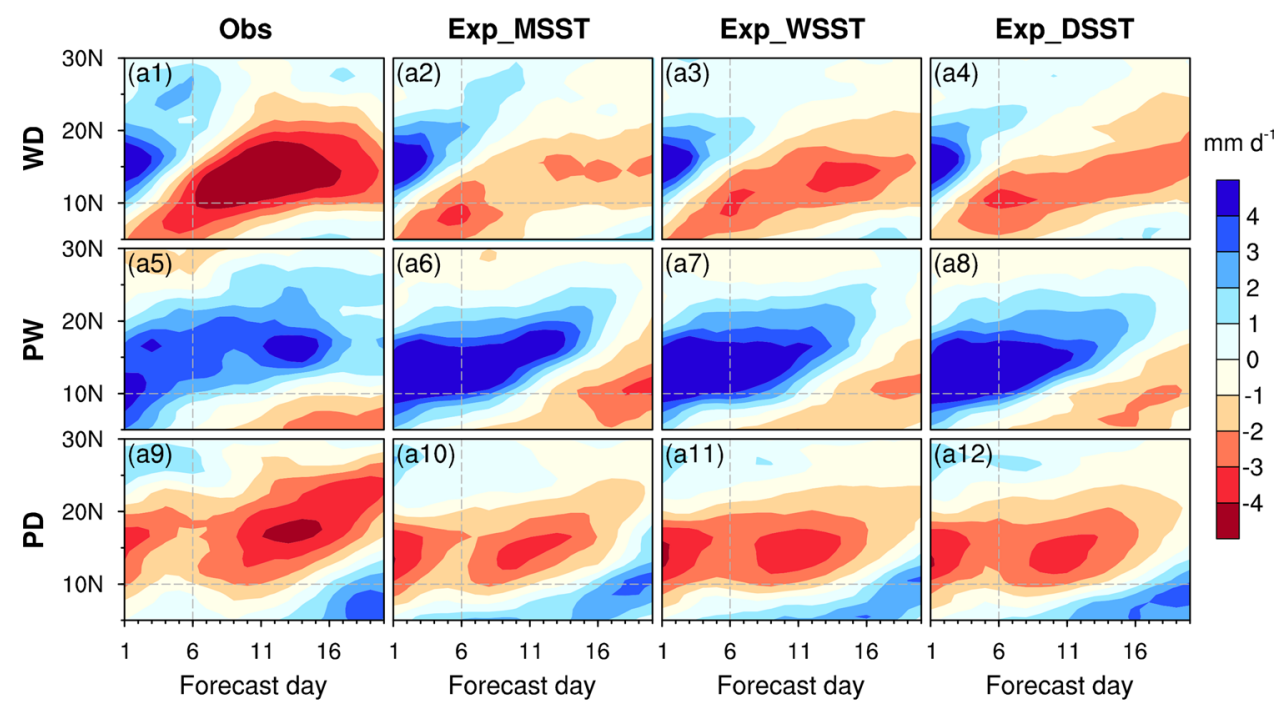

(b) Latent Heat Flux

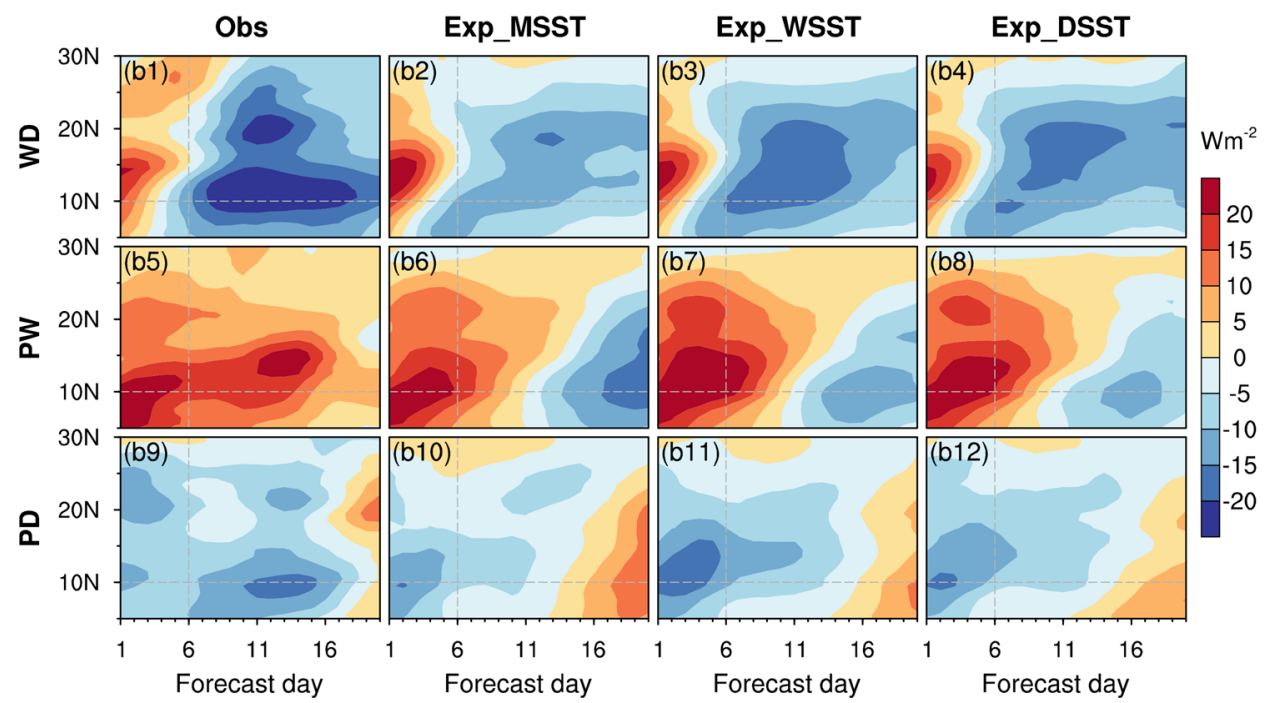

Publisher's Note Springer Nature remains neutral with regard to jurisdictional claims in published maps and institutional affiliations. 